\title{
Monosegemented Flow Potentiometric Titration for the Determination of Chloride in Milk and Wine
}

\author{
Jonas A. Vieira ${ }^{a, b}$, Ivo M. Raimundo Jr. ${ }^{*, a}$, Boaventura F. Reis ${ }^{c}$, M. Conceição B.S.M. Montenegro ${ }^{d}$ \\ and Alberto N. Araújo ${ }^{d}$ \\ ${ }^{a}$ Instituto de Química, Universidade Estadual de Campinas, CP 6154, 13084-971 Campinas - SP, Brazil \\ ${ }^{b}$ Instituto de Química, Universidade Federal de Goiás, CP 131, 74001-970 Goiânia - GO, Brazil \\ ${ }^{c}$ Centro de Energia Nuclear na Agricultura, Universidade de São Paulo, Av. Centenário, 303, \\ 13400-961 Piracicaba - SP, Brazil \\ ${ }^{d}$ CEQUP - Departamento de Química-Física, Faculdade de Farmácia, Universidade do Porto, \\ Rua Aníbal Cunha, 164-4050 Porto, Portugal
}

\begin{abstract}
Este trabalho descreve um procedimento automático em fluxo monossegmentado para titulação potenciométrica aplicado à determinação de cloreto em leite e vinho. O sistema de fluxo foi desenvolvido com base em uma válvula solenóide de 6 vias, controlada por um microcomputador através de um programa escrito em VisualBasic 3.0. Um eletrodo indicador tubular de $\mathrm{Ag}_{2} \mathrm{~S}$ seletivo a $\mathrm{Cl}^{-}$e um eletrodo de referência convencional de $\mathrm{Ag} / \mathrm{AgCl}$ foram empregados. Um algoritmo baseado na diferença de potencial entre duas adições subsequentes de titulante foi desenvolvido, possibilitando a determinação do ponto final da titulação em, no máximo, 10 tentativas, com uma precisão melhor que $1,0 \%$. O sistema proposto foi avaliado pela determinação de cloreto em leite e vinho, usando uma solução padrão de $\mathrm{AgNO}_{3}$ como titulante. A exatidão foi avaliada comparando-se os resultados com aqueles obtidos pelo método da AOAC, não sendo encontradas diferenças significativas ao nível de confiança de $95 \%$.
\end{abstract}

An automated flow potentiometric titration procedure for the determination of chloride in milk and wine exploiting the monosegmented flow approach is described. The flow network was designed based on a six-way solenoid valve, controlled by a microcomputer running software written in

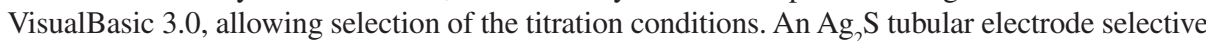
for $\mathrm{Cl}^{-}$and a conventional $\mathrm{Ag} / \mathrm{AgCl}$ electrode were employed as indicator and reference, respectively. An algorithm based on the potential difference between two subsequent titrant additions was developed, allowing to reach the end point in less than 10 attempts, with a precision better than $1.0 \%$. The proposed system was evaluated by determining chloride in milk and wine, using a standard $\mathrm{AgNO}_{3}$ solution as titrant. Accuracy was ascertained by comparing the results with those obtained using the AOAC procedure. No significant difference at a $95 \%$ confidence level was observed.

Keywords: potentiometric titration, monossegmented flow, multicommutation, ion selective electrode, chloride in milk, chloride in wine

\section{Introduction}

The mechanisation of the potentiometric titration procedure was first described in $1914^{1}$ and the introduction of flow injection analysis in $1975^{2}$ improved this mechanisation, including for potentiometric and spectrophotometric titrations..$^{3-5}$ Flow injection titration usually employs a calibration step, in which the peak width

*e-mail: ivo@iqm.unicamp.br (instead of height) is taken as the analytical parameter. The simplest approach, which was first proposed by Ruzicka et al. ${ }^{6}$ in 1977, employs a single line manifold and is still being employed nowadays. 7,8

Different alternatives have been proposed to determine the stoichiometric point in a flow titration procedure. Continuous flow systems based on the ratio of sample and titrant flow rates have been exploited to achieve the end point. ${ }^{9,10}$ In order to vary the flow rates of the solutions independently, two peristaltic pumps are necessary, which 
represents the main drawback of these systems. Similar approaches to perform titrations have also been proposed based on triangle-programmed flow. ${ }^{11,12}$

Some attempts have been described in the literature in order to avoid the calibration step with a standard solution in a flow injection titration. Araújo et al..$^{13}$ have proposed the calibration of the concentration gradient which takes place in a flow injection system to determine the end point in conductometric and spectrophotometric titrations. As long as the gradients undergone by standard and sample are the same, the concentration of the sample can be inferred directly from the titration curve obtained with a single injection. Korn et al. ${ }^{14}$ have employed a multicommuted flow system to carry out acid-base titrations, by inserting into the flow path known volumes of sample and titrant solutions by means of a peristaltic pump whose flow rate has been previously calibrated.

The sequential injection analysis (SIA) concept has also been employed to implement flow titration procedures. Although SIA systems provide a different way to process sample and titrant solution, they usually require a calibration step with standard solutions to determine the analyte concentration in the sample. ${ }^{15-17}$ Recently, Arlem and Bartroli ${ }^{18}$ have described a SIA-batch system to perform titrations without the need of a calibration curve while Pimenta et al. ${ }^{19}$ have employed the Gran method to determine the end point of potentiometric titrations.

A multisegmented flow system has been proposed by Fleet and $\mathrm{Ho}^{20}$ to perform flow titration, implemented by keeping the flow rates of sample and titrant solutions constant while the titrant concentration is changed. In this case, a calibration with standard solutions is also necessary to calculate the concentration of the sample.

Recently, monosegmented flow analysis systems ${ }^{21}$ have been exploited for implementation of spectrophotometric and potentiometric titrations. Aquino et al. ${ }^{22}$ have proposed an automatic monosegmented flow titrator, which can perform a true titration according to the IUPAC definition, by employing a single aliquot of sample. Assali et al. ${ }^{23}$ have employed the simultaneous multiple injection concept $^{24}$ to implement a spectrophotometric titration in a monosegmented system. Although a titration curve with a shape similar to that of manual titration is obtained, several injections of sample and titrant must be made in order to obtain the curve; the concentration of the analyte can be straightforwardly determined by knowing the volumes of the injected solutions. The binary search concept ${ }^{14}$ has been utilised by Martelli et al..$^{25}$ to perform acid-base potentiometric titration. In this system, the volume of sample is maintained constant, while the volumes of titrant and an inert diluent solution are varied in order to keep the monosegment volume also constant. The Fibonacci algorithm has been applied by Honorato et al. ${ }^{26}$ to implement acid-base spectrophotometric titrations, in which the volumes of sample and titrant are varied according to the algorithm in order to achieve the end point. A potentiometric methodology based on a successive aproximation algorithm has also been proposed to carry out titration in a monosegmented flow system. ${ }^{27}$

This work describes an automatic sequential injection flow system, which incorporates the monosegmented approach, to perform potentiometric titrations. The end point was achieved by employing a successive approximation strategy and the feasibility of the system was ascertained by determination of chloride in milk and wine, using a tubular silver sulphide indicator electrode.

\section{Experimental}

\section{Reagents and solutions}

All chemicals were of analytical grade, and distilled/ deionised water obtained from a Milli-Q system was used throughout. Silver nitrate and sodium chloride solutions were prepared in the range from $8.0 \times 10^{-4}$ to $3.0 \times 10^{-2} \mathrm{~mol} \mathrm{~L}^{-1}$. $1.0 \times 10^{-1} \mathrm{~mol} \mathrm{~L}^{-1}$ sodium nitrate was used as carrier solution. Concentrated nitric acid in the ratios of $(1+39, \mathrm{v} / \mathrm{v})$ and $(1+4, v / v)$ were used to acidify milk and wine samples, respectively.

\section{Apparatus and flow set up}

The set up was comprised of an IPC8 Ismatec peristaltic pump furnished with Tygon pumping tubes, six port and three-way solenoid valves (NResearch), a home made power supply interface ${ }^{28}$ to match the electric current intensity and voltage required to drive the solenoid valves, a home-made $\mathrm{Ag}_{2} \mathrm{~S}$ tubular electrode constructed as previously described, ${ }^{29}$ a MicropH 2002 Crison potentiometer equipped with an $\mathrm{Ag} / \mathrm{AgCl}$ reference electrode and a Pentium microcomputer equipped with a PCL-711S (Advantech) electronic interface card. The software to control the system was written in VisualBasic 3.0. Reaction coils and flow lines were of PTFE tubing, with internal diameters of $1.6 \mathrm{~mm}$ and $0.8 \mathrm{~mm}$.

A diagram of the system is depicted in Figure 1. The core of the manifold was the sampling valve (V1) that comprises six normally closed ports, controlled by solenoids. Each port can be individually opened (switching on its solenoid), allowing the fluid to flow through its inner channel towards the central port (V1). In the configuration shown, the port P6 is opened to permit 


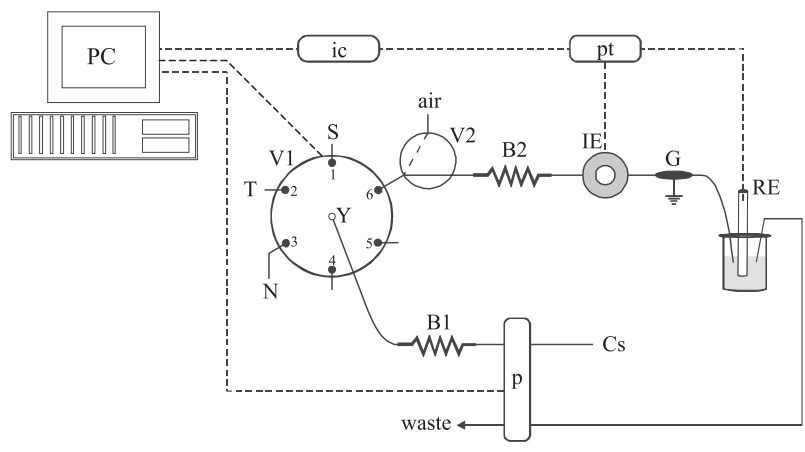

Figure 1. Diagram of the flow titration system. PC, microcomputer; ic, electronic interface; pt, potentiometer; V1, six-port solenoid valve; $\mathrm{V} 2$, three-way solenoid valve; $\mathrm{IE}, \mathrm{Ag}_{2} \mathrm{~S}$ tubular indicator electrode; $\mathrm{G}$, ground; $\mathrm{RE}, \mathrm{AgCl}$ reference electrode; p, peristaltic pump; $\mathrm{B} 1$, $0.7 \mathrm{~mm}$ id PTFE holding coil; B2, $1.6 \mathrm{~mm}$ id PTFE reaction coil; Cs, $\mathrm{NaNO}_{3}$ carrier solution; $\mathrm{S}$, sample solution; T, titrant solution; $\mathrm{N}$, nitric acid solution.

communication with the central port, allowing the carrier solution (Cs) to be pumped through the coils B1 (holding coil, id $0.8 \mathrm{~mm}$ ) and B2 (reaction coil, id $1.6 \mathrm{~mm}$ ), towards the indicator (IE) and reference (RE) electrodes. A $10 \mathrm{~mm}$ long stainless steel tube $(G)$ is placed between these electrodes and connected to ground in order to minimise the electrical noise. The three-way solenoid valve (V2) is employed to insert the air bubbles of the monosegment (ports 4 and 5 must be filled with sodium nitrate carrier solution to avoid the introduction of spurious air bubbles during valve commutation). The dashed lines in Figure 1 indicates the connections of the microcomputer with the peristaltic pump (through a RS232 serial interface), solenoid valves and potentiometer (through the PCL711 parallel interface, IC).

To perform a titration, the software requests the control variables comprising pumping flow rate (rotation speed of the peristaltic pump), time intervals in which the ports of the valves are switched on, ports of the valve V1 to be selected for sample/titrant insertion, and precision for determination of the titration end point. Afterwards, all the steps of the titration procedure are carried out automatically, including variation of the volumes of sample and titrant solutions to be inserted into reaction coil B1 and also the decision concerning the end of the titration procedure. While the analytical procedure is run, a plot of the signal generated by the detector is displayed on the microcomputer video screen as a time function to allow its visualisation in real time.

\section{Titration procedure}

The titration procedure was implemented exploiting a successive approximation strategy as depicted in Figure 2. Therefore, several analytical runs (henceforth referred as trials) must be carried out to locate the end point of the titration. Each trial is done by switching on the solenoids of the sampling valve (Figure 1) that enable (open) the ports assigned as P1, P2, P3 and P6 and comprises one loading and one reading step.

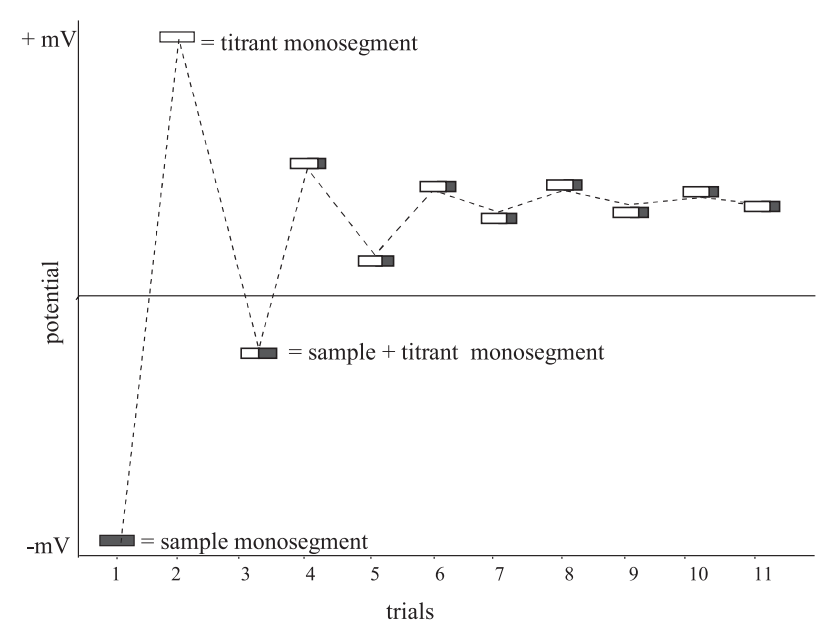

Figure 2. Representation of the titration process, indicating the convergence of the potential to the stoichiometric point as a function of the number of trials.

In the first trial, to carry out the loading step, the pumping direction is reversed and valve V2, port P1 and valve $\mathrm{V} 2$ are switched on in this sequence by intervals of time of $\Delta \mathrm{t}_{\mathrm{b}}, \Delta \mathrm{t}_{\mathrm{s}}$ e $\Delta \mathrm{t}_{\mathrm{b}}$, respectively. Port P6 is opened together with valve V2. Under this condition, a sample solution aliquot with volume $\mathrm{V}_{\mathrm{s} 0}=\varphi \Delta \mathrm{t}_{\mathrm{s} 0}(\varphi=$ flow rate $)$ is inserted into coil B1, sandwiched between two air bubbles with volumes $\mathrm{V}_{\mathrm{b}}=\varphi \Delta \mathrm{t}_{\mathrm{b}}$. Afterwards, the pumping direction is reversed, port P6 is opened and the sample zone is displaced from coil B1 through coil B2, towards the detection system. After the first air bubble of the monosegment reaches the vessel where the reference electrode is immersed, the electrical contact between this electrode with the indicator electrode is re-established and the potential difference of the cell (S0) is measured.

In the second trial, to carry out both loading and reading steps the system operation is identical to the first one, excepting that port $\mathrm{P} 2$ is opened instead of port $\mathrm{P} 1$. In this way, an aliquot of the titrant solution with volume $\mathrm{V}_{\mathrm{t} 0}=\varphi$ $\Delta \mathrm{t}_{\mathrm{t} 0}\left(\Delta \mathrm{t}_{\mathrm{t} 0}=\Delta \mathrm{t}_{\mathrm{s} 0}\right)$ is processed. The reading step is carried out as described for the first trial and the measurement is assigned as $\mathrm{S} 1$. The reading step strategy is maintained to locate the end point of the titration and the measurements are assigned as $\mathrm{S} 1, \mathrm{~S} 2, \ldots, \mathrm{Sj}$, where $\mathrm{j}$ is the number of trials. 
In the third trial, aliquots of sample and titrant solutions of equal volumes $\left(\mathrm{V}_{\mathrm{t} 1}=\mathrm{V}_{\mathrm{s} 1}=\varphi \Delta \mathrm{t}_{\mathrm{s} 1} ; \Delta \mathrm{t}_{\mathrm{s} 1}=\Delta \mathrm{t}_{\mathrm{s} 0} / 2\right)$ is inserted into coil B1, sandwiched between two air bubbles, by sequentially opening valve V2, ports $\mathrm{P} 1$ and $\mathrm{P} 2$, and valve V2. The difference of potential measured (S2) is then compared with S0 and S1 in order to decide if the aliquot of titrant must be increased or decreased in the next trial. If the condition $|\mathrm{S} 2-\mathrm{S} 1|>|\mathrm{S} 2-\mathrm{S} 0|$ is obtained, then an excess of sample solution remained in the monosegment. In this case, the volume of the titrant solution is increased by $\Delta \mathrm{V}=\left(\mathrm{V}_{\mathrm{t} 0}-\mathrm{V}_{\mathrm{t} 1}\right) / 2$ and sample solution is decreased by the same amount, because the volume of the monosegment must be constant $\left(\mathrm{V}=\mathrm{V}_{\mathrm{t}}+\mathrm{V}_{\mathrm{s}}\right)$. On the other hand, if the condition $|\mathrm{S} 2-\mathrm{S} 1|<|\mathrm{S} 2-\mathrm{S} 0|$ is obtained, then an excess of titrant solution remained. Therefore, the volumes of sample and titrant solutions must be decreased and increased, respectively, by the same amount $(\Delta \mathrm{V})$, as described above. This strategy is carried out until attaining the stoichiometric point. Generalising for the jth trial, the increasing/decreasing amounts $\left(\Delta \mathrm{V}_{\mathrm{n}}\right)$ can be presented by the equation $\Delta \mathrm{V}_{\mathrm{n}}=\left|\left(\mathrm{V}_{\mathrm{tj}}-\mathrm{V}_{\mathrm{tj}-1}\right)\right| / 2$, where $\mathrm{V}_{\mathrm{tj}}$ and $\mathrm{V}_{\mathrm{t} j-1}$ are the volumes of the titrant solution used in the jth and jth- 1 trials. The procedure is ended when the relative signal variation defined as $\delta=\left(\left|\mathrm{S}_{\mathrm{j}}-\mathrm{S}_{\mathrm{j}-1}\right| / \mathrm{S}_{\mathrm{j}}\right)$ is lower than a preset value.

The flow rate during sampling step was maintained at $32 \mu \mathrm{L} \mathrm{s}^{-1}$ and the time interval to load sample or titrant solutions (or both) was set at $8 \mathrm{~s}$, therefore the volume of the segment $\left(\mathrm{V}=\mathrm{V}_{\mathrm{t}}+\mathrm{V}_{\mathrm{s}}\right)$ comprising aliquots of sample and titrant solutions inserted into coil B1 was $256 \mu \mathrm{L}$. The assays to optimise the operational conditions were carried out using a $1.0 \times 10^{-3} \mathrm{~mol} \mathrm{~L}^{-1}$ standard $\mathrm{NaCl}$ solution and as titrants $1.0 \times 10^{-3}, 2.0 \times 10^{-3}$ and $1.0 \times 10^{-2} \mathrm{~mol} \mathrm{~L}^{-1}$ $\mathrm{AgNO}_{3}$ solutions.

\section{Results and Discussion}

The procedure employed to determine the end point of the titration was based on a successive approximation strategy, following the steps described in the experimental section. Figure 2 depicts a hypothetical titration profile, showing that the potential generated by the indicator electrode converges to a constant value (the end point potential), which indicates that sample and titrant are sampled in a ratio close to the stoichiometric ratio. To demonstrate this model, some assays were carried out using a $1.0 \times 10^{-3} \mathrm{~mol} \mathrm{~L}^{-1}$ standard $\mathrm{NaCl}$ solution and a $2.0 \mathrm{x}$ $10^{-3} \mathrm{~mol} \mathrm{~L}^{-1} \mathrm{AgNO}_{3}$ solution as sample and titrant, respectively. The flow rate and monosegment volume were maintained at $32 \mu \mathrm{L} \mathrm{s}^{-1}$ and $256 \mu \mathrm{L}$, respectively, and the end point was determined by varying the ratio of sample and titrant volumes. Table 1 shows the volumes of titrant necessary to reach the end point obtained using three different criteria for the stopping condition. The $\delta$ value is set by the user and is defined as the relative difference between two successive attempts, $\delta=100\left(\left|\mathrm{~S}_{\mathrm{j}}-\mathrm{S}_{\mathrm{j}-1}\right| / \mathrm{Sj}\right)$, providing precision in the end point determination. Considering the results shown in this table, it can be deduced that the volume variation $\Delta \mathrm{V}_{\mathrm{n}}=100 / \mathrm{V}_{\mathrm{tj}}-\mathrm{V}_{\mathrm{tj}-1} \mathrm{I} / \mathrm{V}_{\mathrm{tj}}$ fulfils the condition set to end the titration run and, as a consequence, the volume of titrant solution tends to the same value.

Table 1. Effect of the stop condition on the titrant volume at the end point.

\begin{tabular}{cccc}
\hline Trial & $\begin{array}{c}\text { Titrant } \\
\text { volume }(\mu \mathrm{L}) \\
\delta=3 \%\end{array}$ & $\begin{array}{c}\text { Titrant } \\
\text { volume }(\mu \mathrm{L}) \\
\delta=2 \%\end{array}$ & $\begin{array}{c}\text { Titrant } \\
\text { volume }(\mu \mathrm{L}) \\
\delta=1 \%\end{array}$ \\
\hline 1 & 256 & 256 & 256 \\
2 & 128 & 128 & 128 \\
3 & 64 & 64 & 64 \\
4 & 80 & 80 & 80 \\
5 & 88 & 88 & 88 \\
6 & 92 & 92 & 92 \\
7 & & 90 & 90 \\
8 & & $90^{\mathrm{a}}$ & $90^{\mathrm{a}}$ \\
9 & & & 88 \\
\hline
\end{tabular}

aThe predicted end point volume provided by the software is $88.998 \mu \mathrm{L}$.

Similar assays were carried out using sample and titrant solutions with different concentrations yielding the results shown in Figure 3. The end points found were in agreement with the expected values that were set prior to begining the titration. These results indicate that samples with chloride concentrations ranging from $8.0 \times 10^{-4}$ to $3.0 \mathrm{x}$ $10^{-2} \mathrm{~mol} \mathrm{~L}^{-1}$ can be titrated using a single $\mathrm{Ag}^{+}$titrant solution with a concentration around $1.0 \times 10^{-2} \mathrm{~mol} \mathrm{~L}^{-1}$. Analysing these data it can be affirmed that results with acceptable accuracy can be obtained when the concentration ratio of sample and titrant solutions is lower than 40 (that is, the solution of higher concentration must be less than 40 times more concentrated than the lower one). Nevertheless, this range can be extended by increasing the volumes of the titrand plus titrant solutions (the total volume of the monosegment), since the smallest aliquot of solution that can be sampled is constant $(6.4 \mu \mathrm{L})$.

The concentrations of sample and titrant are potential restrictive factors for the system, as the solid formed by the precipitation reaction could clog the tubing, the tubular electrode or the six-way solenoid valve. This limitation has been observed by other authors. ${ }^{30}$ In the present work, solutions with concentrations lower than $3.0 \times 10^{-2} \mathrm{~mol} \mathrm{~L}^{-1}$ could be employed without risks of clogging the system. 


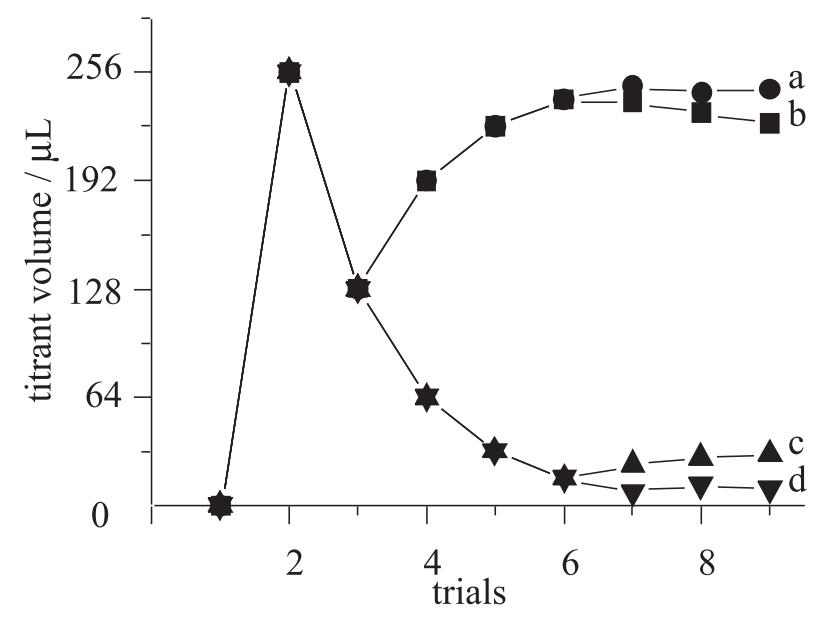

Figure 3. Evaluation of titration end point detection using solutions with different concentrations. (a) $3.0 \times 10^{-2} \mathrm{~mol} \mathrm{~L}^{-1} \mathrm{Cl}^{-}$vs. $8.0 \times 10^{-4}$ mol L-1 $\mathrm{Ag}^{+}$; (b) $1.0 \times 10^{-2} \mathrm{~mol} \mathrm{~L}^{-1} \mathrm{Cl}^{-}$vs. $8.0 \times 10^{-3} \mathrm{~mol} \mathrm{~L}^{-1} \mathrm{Ag}^{+}$; (c) $1.0 \times 10^{-3} \mathrm{~mol} \mathrm{~L}^{-1} \mathrm{Cl}^{-}$vs. $1.0 \times 10^{-2} \mathrm{~mol} \mathrm{~L}^{-1} \mathrm{Ag}^{+}$; (d) $8.0 \times 10^{-4} \mathrm{~mol} \mathrm{~L}^{-1} \mathrm{Cl}^{-}$ vs. $3.0 \times 10^{-2} \mathrm{~mol} \mathrm{~L}^{-1} \mathrm{Ag}^{+}$.

Some experiments were also performed employing the SIA approache. In this case, the $1.6 \mathrm{~mm}$ id reaction coil was changed to $0.7 \mathrm{~mm}$ id PTFE tubing, keeping the same volume for the reactor. These experiments were carried out using $1.00 \times 10^{-3} \mathrm{~mol} \mathrm{~L}^{-1} \mathrm{Cl}^{-}$and $\mathrm{Ag}^{+}$standard solutions, maintaining the total volume of the sample zone (sample plus titrant) at $192 \mu \mathrm{L}$ (time interval of $6 \mathrm{~s}$ ). Therefore, the stoichiometric point was expected to be reached when sample and titrant volumes were $96 \mu \mathrm{L}$. While for the MSFA system the best approximation obtained was $95.4 \mu \mathrm{L}$ of titrant solution, for the SIA system a convergence towards the correct value was not observed, as can be seen in Figure 4. The main drawback of the SIA system arises from the fact that the ratio of the volumes of sample and titrant is

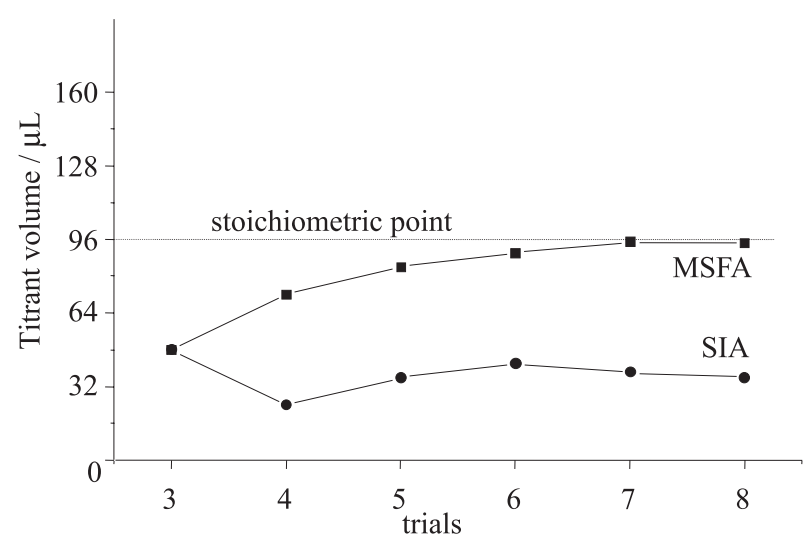

Figure 4. Titration of a $1.0 \times 10^{-3} \mathrm{~mol} \mathrm{~L}^{-1} \mathrm{Cl}^{-}$solution with a $1.0 \times 10^{-3}$ mol L-1 $\mathrm{Ag}^{+}$solution employing the monosegmented (MSFA) and conventional SIA approaches. changed during the titration. Therefore, the interface between sample and titrant is located at different points as the titration is being performed, changing sample/titrant dispersion (since an infinite volume condition is not employed). As a consequence, the measurement of the cell potential is taken at different conditions for different trials, converging to an incorrect value. On the other hand, the MSFA approach provides accurate results, as the monossegment is completely homogeneous due to the air bubbles, which avoid sample dispersion.

The proposed MSFA titration system was assessed by determining chloride in milk and wine. The AOAC methods $^{31,32}$ were taken as reference, which were also adapted to flow system conditions. It must be remembered that pre-treatment is not necessary for either milk or wine samples, and nitric acid was added to the monosegment in the sampling step. Table 2 lists the results obtained with the flow and the manual method, which do not differ significantly at a confidence level of $95 \%$. The precision for determination of the end point (stop condition) was set in $1.0 \%$, providing sample throughputs of eight and ten samples hour ${ }^{-1}$ for milk and wine, respectively. The lower analytical frequency for milk is due to coagulation, which takes place when the nitric acid is added, requiring a longer reaction coil to provide a proper mixing of sample and titrant.

Table 2. Determination of chloride in wine and milk, obtained with the proposed flow system and with the reference method. Concentration of the $\mathrm{AgNO}_{3}$ titrant solutions: $1.00 \times 10^{-2} \mathrm{~mol} \mathrm{~L}^{-1}$ and $8.56 \mathrm{x}$ $10^{-2} \mathrm{~mol} \mathrm{~L}^{-1}$ for the wine and milk determinations, respectively. Results expressed as an average of three determinations \pm estimated standard deviation.

\begin{tabular}{lccc}
\hline sample & $\begin{array}{c}\mathrm{Cl}^{-}\left(\mathrm{mg} \mathrm{L}^{-1}\right) \\
\text { Reference }\end{array}$ & $\begin{array}{c}\mathrm{Cl}^{-}\left(\mathrm{mg} \mathrm{L}^{-1}\right) \\
\text { MSFA }\end{array}$ & $\begin{array}{c}\text { deviation } \\
(\%)\end{array}$ \\
\hline Wine 1 & $10.5 \pm 0.9$ & $10.3 \pm 0.8$ & -2.0 \\
Wine 2 & $18.2 \pm 0.7$ & $19.4 \pm 0.1$ & +5.9 \\
Wine 3 & $37.9 \pm 1.7$ & $38.3 \pm 1.3$ & +1.1 \\
Wine 4 & $57.8 \pm 0.1$ & $60.4 \pm 7.1$ & +4.5 \\
Milk 1 & $999 \pm 4$ & $1001 \pm 5$ & +0.2 \\
Milk 2 & $1121 \pm 3$ & $1125 \pm 9$ & +0.4 \\
Milk 3 & $1107 \pm 6$ & $1125 \pm 9$ & +1.6 \\
Milk 4 & $1142 \pm 3$ & $1114 \pm 7$ & -2.5 \\
\hline
\end{tabular}

a AOAC method, references 31 and 32 .

The analytical performance of the proposed system is comparable to monosegmented titrators described in the literature, $, 2,23,25-27$ presenting an advantage when compared with ordinary sequential injection analysis titration systems, ${ }^{15-17}$ since it does not need a calibration step with standard solutions. 


\section{Conclusions}

A MSFA system was developed to perform automatic titrations based on a successive approximation approach to determine the end point, which can be reached in less than 10 trials, with a precision better than $1.0 \%$. The results were compared with those obtained by the AOAC reference method and no significance differences were found at a 95\% confidence level. Finally, the proposed system does not need a calibration step, usually employed in flow titration methodologies. Therefore, it can be affirmed that the monosegmented flow system implemented by multicommutation is a powerful tool to carry out automatic titration procedures.

\section{Acknowledgments}

Authors thank to Prof. C.H. Collins for manuscript revision. J.V.A. is grateful to FAPESP for the fellowship (Proc. 97/03309-8).

\section{References}

1. Ziegel, H.Z.; Anal. Chem. 1914, 53, 755.

2. Ruzicka, J.; Hansen, E.H.; Anal. Chim. Acta 1975, 78, 145.

3. Etxebarria, M.B.; Lima, J.L.F.C.; Conceição, M.; Montenegro, M.C.B.S.M.; Perez-Olmos, R.; Anal. Sci. 1997, 13, 89.

4. Trojanowicz, M.; Matszewski, W.; Hulanicki, A.; Anal. Chim. Acta 1982, 136, 85.

5. Jyonosono, K.; Imato, T.; Imazumi, N.; Nakanishi, M.; Yagi, J.; Anal. Chim. Acta 2001, 438, 83.

6. Ruzicka, J.; Hansen, E.H; Mosback, H.; Anal. Chim. Acta 1977, 91, 87 .

7. Couto, C.M.C.M.; Lima, J.L.F.C.; Montenegro, M.C.B.S.M.; Analusis 1998, 26, 182.

8. Conceição, A.C.; Santos, M.M.C.; Gonçalves, M.L.S.S.; Santos, F.J.V.; Talanta 2000, 50, 1245.

9. García, I.L.; Viñas, P.; Campillo, N.; Córdoba, M.H.; Anal. Chim. Acta 1995, 308, 67.

10. Marcos, J.; Ríos, A.; Valcárcel, M.; Anal. Chim. Acta 1992, $261,489$.

11. Nagy, G.; Tóth, K.; Pungor, E.; Anal. Chem. 1975, 47, 1460.
12. Yarnitzky, C.N.; Klein, N.; Cohen, O.; Instrum. Sci. Technol. 1995, 23, 91.

13. Araújo, M.C.U.; Santos, A.V.; Honorato, R.S; Pasquini, C.; J. Autom. Chem. 1997, 19, 157.

14. Korn, M.; Gouveia, L.F.B.P.; Oliveira, E.; Reis, B.F.; Anal. Chim. Acta 1995, 313, 177.

15. Maskula, S.; Nyman, J.; Ivaska, A.; Talanta 2000, 52, 91.

16. Estela, J.M.; Mas, F.; Cladera, A.; Cerdá, V.; Lab. Robot. Autom. 1999, 11, 207.

17. Sultan, S.M.; Hassan, Y.A.M.; Ibrahim, K.E.E.; Analyst 1999, 124, 917.

18. Alerm, L.; Bartrolí, J.; Anal. Chem. 1996, 68, 1394.

19. Pimenta, A.M.; Araújo, A.N.; Montenegro, M.C.B.S.M.; Anal.Chim. Acta 2001, 438, 31.

20. Fleet, B.; Ho, A.Y.W.; Anal. Chem. 1974, 46, 9.

21. Pasquini, C.; Oliveira, W. A.; Anal. Chem. 1985, 57, 2575.

22. De Aquino, E.V.; Rohwedder, J.J.R.; Pasquini, C.; Anal. Chim. Acta 2001, 438, 67.

23. Assali, M.; Raimundo Jr.; I.M.; Facchin, I.; J. Autom. Meth. Manag. Chem. 2001, 23, 83.

24. Brito, V.O.; Raimundo Jr, I.M.; Anal. Chim. Acta 1998, 371, 317.

25. Martelli, P.B.; Reis, B.F.; Korn, M.; Lima, J.L.F.C.; Anal. Chim. Acta 1999, 387, 165.

26. Honorato, R.S.; Araújo, M.C.U.; Veras, G.; Zagatto, E.A.G.; Lapa, R.A.S.; Lima, J.L.F.C.; Anal. Sci. 1999, 15, 14.

27. Ganzarolli, E.M.; Lehmkuhl, A.; Queiroz, R.R.R.; Souza, I.G.; Quim. Nova 1999, 22, 53.

28. Reis, B.F.; Giné, M.F.; Zagatto, E.A.G.; Lima, J.LF.C.; Lapa, R.A.; Anal. Chim. Acta 1994, 293, 129.

29. Ferreira, I.M.P.V.O.; Lima, J.L.F.C.; Rangel, A.O.S.S.; Food Chem. 1994, 50, 423.

30. De Aquino, E.V.; Pasquini, C.; Rohwedder, J.J.R.; Raimundo Jr., I.M.; Montenegro, M.C.B.S.M.; Araújo, A.N.; J. Braz. Chem. Soc., submitted.

31. Clifford, C.E.; J. Assoc. Off. Anal. Chem. 1966, 49, 498.

32. Tanner, J.T.; Barnet, S.A.; J. Assoc. Off. Anal. Chem. 1986, 69, 777.

Received: October 19, 2002

Published on the web: March 28, 2003

FAPESP helped in meeting the publication costs of this article. 